\title{
Model of radiocesium transfer from soil to understorey in forest ecosystems
}

\author{
A.V. Konoplev, R. Avila and A.A. Bulgakov \\ Centre for Environmental Chemistry of SPA "Typhoon", 82 Lenin AV., \\ 249038 Obninsk, Kaluga Region, Russia \\ 1 Swedish Radiation Protection Institute, 17116 Stockholm, Sweden
}

\begin{abstract}
The mobility and bioavailability of radionuclides of accidental origin is determined by an initial ratio of their chemical forms in fallout, kinetics of transformation processes and environmental characteristics influential in transfer and distribution of radionuclides between environmental compartments. The objective of the paper is the development and validation of dynamic process-level model FORSUN to describe radiocaesium transfer from soil to plants and fungi in forest ecosystems. The following specific aims were pursued: 1) investigation of mechanisms of radiocaesiun plant uptake, in particular, analysis of a possible role of fungi mycelium as a mediator in its transfer from soil to plant; 2) qualitative and quantitative description of long-term changes of radiocaesitum content in understorcy compartments of forest ecosystems; 3) prediction of ${ }^{137} \mathrm{Cs}$ activity concentrations in berries and mushrooms on the basis of a minimum of fitting paramelers.

A distinctive feature of model is taking into consideration vertical redistribution of radionuclide in a root layer of soil as goveraing factor of changes of the soil-understorey concentration ratios during first 10-30 years afler the accident. The model uses paratreterization of soil-plant concentration ratio through the key physico-chemical chasacteristics of soils determining its biological availability: a stcady state portion of exchangeable caesium to soil and content of exchangeable calcium. The method for calculating radiocaesium accumulation parameters in forest fungi by soil properties is proposed based on the potassium contents in specific fungi and soil, and also steady-state portion of exchangeable caesium in soil.
\end{abstract}

\section{INTRODUCTION}

The major radiation accidents of the latest decades necessitated long-term prediction of radionuclides migration in the environment and in food chains with a view to providing support to decision making with respect to measures in contaminated areas reducing radiation risk for the public.

Such prediction is based on using mathematical models accounting for mechanisms of migration and transformation of various species of radionuclides. Mobility and biological availability of accident origin radionuclides are governed by the initial ratio of species in depositions, the kinetics of transformation processes and characteristics of the environment influencing transfer and distribution of radionuclides among different media. The goal of this work is to develop and validate a dynamic model of radiocesium transfer from soil to plants and to fungal fruit bodies in forest ecosystems. In doing this, the following tasks are addressed in:

examination of the mechanism underlying radiocesium transfer from forest soils to plant, and in particular study of a possible role of fungal mycelium as an intermediate in radionuclide transfer from soil to plants;

qualitative characterization and quantification of long-term changes in radiocesium distribution in the system «soil-plant» of forest ecosystems;

prediction of ${ }^{137} \mathrm{Cs}$ concentration in forest plants and fungi using the least possible number of calibration parameters.

\section{MODEL DESCRIPTION}

The concept of the proposed model FORSUN is schematically presented in Fig 1 . Numerical implementation of this model is based on using the program STELLA 5.0. For more detailed characterization, some of the model compartments can be subdivided into smaller components. For example, the compartment "Plant» can be divided to include subcompartments «Root exchange complex", «Root» and « Above-ground plant». The vertical migration of radionuclides in soil and variations of soil 
characteristics with depth can be considered more fully by subdividing the compartments Soil 1 (S1) and Soil 2 (S2) into several subcompartments (layers). The level of detail and hence complexity of the model will be dependent on modelling goals and availability of data about characteristics of soil, plants and fungi. With this in mind, using genetic soil horizons as separate compartments of the model seems to be best suited to our purposes.
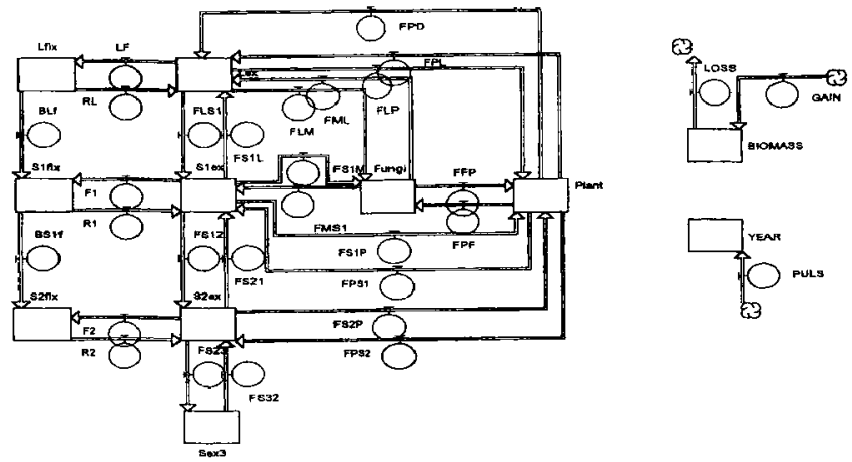

Figure 1: Conceptual structure of dynamic model FORSUN of radiocesium transfer from foil to plants/mushrooms in forest.

Taking into consideration high uptake of radiocesium by fungi and an extensive surface area of mycelium in soil, as well as its symbiotic coupling with plant root systems through mycorhiza, many researchers $[1,2]$ believe the transfer from fungal mycelium through mycorhiza to be the primary mechanism of root transfer of radiocesium in forest ecosystems. There are indications that $50 \%$ and more of the radiocesium repository in forest soils is concentrated in fungal mycelium [1]. However, up till now no direct experimental evidence exists confirming radiocesium transfer from fungal mycelium to plant via mycorhiza. What is more, there is actually evidence in contraction of this hypothesis:

1. If this mechanism of radiocesium transfer to plants were predominant, contamination levels of plants and fungi would be expected to change concurrently, which, however, was not the case based on the 1987-1990 data for the contaminated areas of the Bryansk region of Russia [3]. In the Bryansk region the ${ }^{137} \mathrm{Cs}$ concentration was growing during the $4-5$ years after the Chemobyl accident for all main species of fungi, while the ${ }^{137} \mathrm{Cs}$ concentration in plants was declining in the same time period.

2. Experimental data $[4,5]$ suggest that the concentration factor of $137 \mathrm{Cs}$ in meadow soils with mycelium is lower than that in meadow soils without mycelium. In the author's view, this may be indicative of immobilization or biological fixation of $137 \mathrm{Cs}$ by fungal mycelium in soil. Similar results were obtained for plants infected with mycorhiza and without mycorhiza grown in nutrient solutions [6]

3. According to the data of [7] the ratios $137 \mathrm{Cs} / 134 \mathrm{Cs}$ and $137 \mathrm{Cs} / 133 \mathrm{Cs}$ are different for fungi and plants, which may suggest the absence of a dominant role of mycelium in transfer to plants. It should be noted, however, that the statistical significance of data regarding such differences is rather doubtful. 
4. At the same time, experiments show [8] that the radiocesium concentration in heath with mycorhiza is up to $40 \%$ higher that in heath without mycorhiza. Increased transfer of ${ }^{134} \mathrm{Cs}$ was reported in three experiments with mycorhiza grafting, but no increase in radiocesium transfer occurred in the fourth one. Thus the currently available data provide no basis for quantification or even qualitative characterization of radiocesium exchange in the system "plant-mycelium». Therefore, one of the objectives of this paper is to develop a tool for identifying the role of mycorhiza in radiocesium transfer to plant and estimate relevant kinetic parameters.

The distinctive feature of the forest understorey is the high mobility and availability of radiocesium occurring there. Our studies of $1987-1988$ suggest that $80-100 \%$ of radiocesium in the litter occurs in mobile forms (water soluble and exchangeable). Some researchers made suggestions even prior to the Chernobyl accident that the radiocesium transfer to plants occurred more vigorously from the litter than from the soil [9]. There is, however, no direct evidence to this hypothesis. The proposed model assumes that radiocesium can be transferred to plant directly from the litter.

All the processes considered in the model are taken to be reversible and are described by the firstorder kinetic equations. The corresponding rate constants are estimated using the system of two equations:

$$
\begin{aligned}
& k_{i j}+k_{f t}=\tau_{i j} \\
& k_{j} k_{i j}=C R_{i j}
\end{aligned}
$$

where $k_{i j}$ and $k_{i j}$ are the rate constants of radiocesium transfer between the compartments $i$ and $j ; \tau_{i j}$ is the time scale of radiocesium exchange between the compartments $\mathrm{i}$ and $\mathrm{j} ; \mathrm{CR}_{\mathrm{ij}}$ is the concentration ratio of radiocesium in the compartments $\mathbf{i}$ and $\mathbf{j}$.

The flux of radiocesium from the compartment $i$ to the compartment $\mathrm{j}\left(\mathrm{F}_{\mathrm{ij}}, \mathrm{Bq} / \mathrm{m}^{2} \mathrm{yr}\right)$ can be written by the equation:

$$
F_{i j}=\tau_{i j}^{-1}\left(I+C R_{\eta j}\right)^{-1}\left(Q_{j}-Q_{j} m_{i j} m_{j}^{-1} C R_{i j}\right)
$$

where $Q_{i}$ and $Q_{j}$ is the radiocesium repository in the compartments $i$ and $j$, respectively, $B q / m^{2} ; m_{i}$ and $m_{j}$ are the masses of the compartments $i$ and $j, \mathrm{~kg} / \mathrm{m}^{2}$ (for biological compartments- biomass as a function of time).

\section{ESTIMATION OF PARAMETERS}

The procedures applied for estimation of parameters of radiocesium migration in soil is described in [10]. The time scale of radiocesium exchange in the system "soil solution-plant (mycelium)» is about 1 day [11]. For the system «soil-plant (mycelium)» this process is somewhat slower and accordingly the characteristic time is taken to be about 1 week.

It is assumed that radiocesium transfer to plant occurs from soil solution by selective (potassium channels) and non-selective (ionic membrane leakage) pathways, and this process is controlled by ionexchange on the wall (apoplast) of root cells [11]. The current quasi-equilibrium content of radionuclide in plant is assumed to be directly proportional to its fraction in the root exchange complex (REC) [12]. Thtus, radiocesium transfer from soil solution to plant can be split into two phases: sorption from soil solution on the root exchangeable complex of a cell wall and transfer through the membrane of a plant cell [13]. The root exchange complex is characterized by its cation exchange capacity. In contrast to soil, the root exchange complex is non-selective with respect to radiocesium $[13,14]$. In this case the concentration factor for forest soils can be written as:

$$
C R-B \times A
$$

where $\mathrm{A}$ is the bioavailability factor of radiocesium in soil, B is the constant for a given plant species. The bioavailability factor can be expressed through the key soil characteristics $[13,15]$ : 


$$
A=\frac{\alpha_{e x} P N A R}{R I P^{e x}}
$$

where $\alpha_{e x}$ is the fraction of exchangeable ${ }^{137} \mathrm{Cs}$ in the root soil layer; $R I P^{\text {ex }}(\mathrm{K})$ is the exchangeable radiocaesium interception potential [16];

$$
P N A R=\frac{[K]_{w}+K_{c}\left(N H_{4} / K\right)\left[N H_{4}\right]}{\sqrt{[C a]+[M g]}}
$$

where $[\mathrm{K}]_{\mathrm{w}},\left[\mathrm{NH}_{4}\right]_{\mathrm{w}},[\mathrm{Ca}]_{\mathrm{w}},[\mathrm{Mg}]_{\mathrm{w}}$ is the concentrations of macro-ions in soil solution; $\mathrm{K}_{\mathrm{c}}\left(\mathrm{NH}_{4} / \mathrm{K}\right)$ is the selectivity coefficient of ammonium with respect to potassium on frayed edge sites

When data on RIP ${ }^{\mathrm{ex}}$ and PNAR are not available a simplified expression for the bioavailability factor can be used [15]:

$$
A^{*}=\frac{10 a_{e x}}{K_{c}^{e f f}(C s / K)\left([C a]_{e x}+[M g]_{e x}\right)}
$$

where $K_{e}{ }^{\text {eff }}(\mathrm{Cs} / \mathrm{K})$ is the effective selectivity coefficient.

The data available in literature $[1,17]$ lead us to assume that the ratio of concentrations of radiocesium and potassium in fungi is directly proportional to their ratio in soil solution with the discrimination coefficient $\mu$ close to unity:

$$
\frac{\left[{ }^{137} C s\right]_{M}}{[K]_{M}}=\mu \frac{\left[{ }^{137} C s\right]_{w}}{[K]_{w}}
$$

where $\left[{ }^{137} \mathrm{Cs}\right]_{\mathrm{M}}$ and $[\mathrm{K}]_{\mathrm{M}}$ are concentrations of ${ }^{137} \mathrm{Cs}$ and $\mathrm{K}$ in fungi (mycelium). Their concentrations in fruitbodies and mycelium are taken to be identical [2]. $\left[{ }^{137} \mathrm{Cs}\right]_{w}$ and $[\mathrm{K}]_{\mathrm{w}}$ are concentrations of ${ }^{137} \mathrm{Cs}$ and $\mathrm{K}$ in soil solution of the fungal mycelium zone; $\mu$ is the discrimination coefficient, and in this particular case $\mu \approx 1$.

Using the equation relating $\left[{ }^{137} \mathrm{Cs}\right]_{\mathrm{w}}$ and $\left[{ }^{1.37} \mathrm{Cs}\right]_{\mathrm{ex}}$ through $\mathrm{RIP}{ }^{\mathrm{ex}}$ we get:

$$
\frac{\left[{ }^{137} C s\right]_{M}}{\left[{ }^{137} C s\right]_{e x}}=\mu \frac{[K]_{M}}{R I P^{e x}}
$$

Therefore, the ${ }^{137} \mathrm{Cs}$ concentration ratio for mushrooms $\left(\mathrm{CR}_{\mathrm{M}}\right)$ can be written for potassium scenario as:

$$
C R_{M}=\alpha_{e x} \mu \frac{[K]_{M}}{R I P^{e x}}
$$

Given no data on RIP $^{\mathrm{cx}}$ are available, a simplified equation can be used

$$
C R_{M}=\alpha_{e x} \mu \frac{[K]_{M}}{K_{c}^{e f f}[K]_{e x}}
$$

Thus, the radiocesium bioavailability factor for fungi can be written as: 


$$
A_{M}=\frac{\alpha_{e x}}{R I P^{e x}}
$$

or in simpler terms:

$$
A^{*}=\frac{\alpha_{e x}}{K_{c}^{e f f}(C s / K)[K]_{e x}}
$$

and the proportionality coefficient $\mathbf{B}_{\mathrm{M}}$ is equal to $\mu[\mathrm{K}]_{\mathrm{M}} \approx[\mathrm{K}]_{\mathrm{M}}$.

\section{MODEL VALIDATION}

The model verification was based on using the data of the scenario $S$ for southern Finland [11] prepared within the program VAMP (IAEA). The model testing and validation was performed by comparison of calculation results with experimental data according to the scenario [19] developed by the Forest Working Group of the BIOMASS (IAEA) Research Program. The calculations were performed using input data only, after that experimental test data were disclosed. Example of the comparison of model calculations for Boletus edulis with test data is presented on Fig. 2.

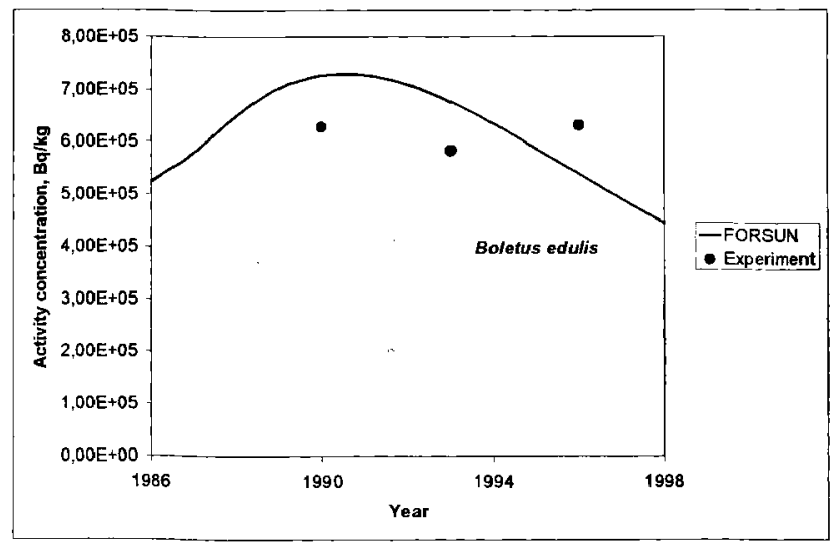

Figure 2: Example of comparison of modelling results (FORSUN) with experimental datia of A. Orlov according to the scenario [19] in frame of BIOMASS Forest Working Group.

The calculations show that when the rate constants of plant-mycelium transfer and plant-soil transfer are close, the time variations of ${ }^{137} \mathrm{Cs}$ in plants correlate with those in fungi. However, if the rate constant of plant-mycelium transfer is much lower than that of plant-soil transfer, the dynamics of ${ }^{137} \mathrm{Cs}$ concentration in plants and fungi is significantly different

Using the parameterization of concentration ratios via soil characteristics allowed us to derive realistic estimates for plants and fungi. Both the estimated absolute concentrations of ${ }^{137} \mathrm{Cs}$ and their variations in time are in good agreement with experimental data. Immediately after the accident the fixation of ${ }^{137} \mathrm{Cs}$ 
results in a decrease in radionuclide transfer to plants and fungi, whereas the migration of ${ }^{137} \mathrm{Cs}$ to deeper soil layers in which the radionuclide is more easily available leads to an increase in such transfer. For plants these two processes are balanced off and therefore ${ }^{137} \mathrm{Cs}$ concentration in plants does not vary significantly in the first years after the accident. On the other hand, for fungi the increase in ${ }^{137} \mathrm{Cs}$ transfer due to vertical migration exceeds the radionuclide decrease due to fixation, and this is associated with the fact that the biological availability factor for fungi (mycelium) grows with depth faster than that for plants.

\section{Acknowledgement}

This work was partly supported by Swedish Radiation Protection Institute and International Atomic Energy Agency.

\section{References}

[1] Olsen R.A., Joner E., Bakken L.R. "Soil fungi and fate of radiocesium in soil ecosystems", The transfer of radionuclides in natural and semi-natural environments, Passariano (Udine), Italy, 11-15 September 1989, Desmet G., Nassimbeni P., Belli M. Eds (Elsevier, London-New York, 1990) pp. $657-663$.

[2] Nikolova I., Johanson K.-J., Dahlberg A., J. Environ. Radioactivity, Volume 17 (1997) 115-125.

[3] Shutov V.N., Bruk G.J., Kaduka M.V., Balonov M.I., Basalaeva L.N., Travnikova I. (1998)

Dynamics of ${ }^{137} \mathrm{Cs}$ transfer factors from soil into forest mustrooms and berries after the Chernobyl accident, IUR Topical Meeting, Mol, June 1998.

[4] Clint G.M., Dighton J., Rees S., Mycological Research Volume 95 (1991) 1047-1051

[5] Dighton J., Clint G.M., Poskitt J. Mycological Research Volume 95 (1991) 1052-1056.

[6] Clint G.M., Dighton J., New Phytology Volume 121 (1992) 555-561

[7] Yoshida S., Muramatsu Y. J. Environ. Radoactivity Volume 41 (1998) 183-205.

[8] Strandberg M., Johansson M. J. Environ. Radoactivity Volume 40 (1998) 174-184.

[9] Firsakova S.K., Grebenshchikova N.V., Reports of VASHNIL No. 9 (1980) 19-22 (In Russian).

[10] Konoplev A.V, Golubenkov A A., Meteorology and Hydrology No. 10 (1991) 62-68 (In Russian).

[11] Sokolik A.I., Demko G.G., Gorobchenko N.E., Yurin V.M., Radiation Biology. Radioecology, Volume 37 (1997) 787-795 (In Russian)

[12] Haynes, R.J. Bot. Rev. Volume 46 (1980) 75-99.

[13] Konoplev A. V., Konopleva I.V., Radiation Biology. Radioecology Volume 39 (1999) 455-461 (In Russian).

[14] Smolders E., Sweeck L., Mercks R., Cremers A. J. Environ.Radioact. Volume 37 (1997) 161-170.

[15] Konoplev A V., Avila R., Bulgakov A.A., Johanson K-J., Konopleva I.V., Popov V.E. Radiochim. Acta Volume 88 (2000) 789-792.

[16] Konoplev A.V., Konopleva I. V., Geochemistry No. 2 (1999) 207-214 (In Russian).

[17] Perkins J., Gadd G.M. Mycological Research Volume 97 (1993) 717-724.

[18] IAEA-TECDOC-904. Validation of models using Chernobyl fallout data from southern Finland. IAEA, Vienna, 1996, $483 \mathrm{p}$.

[19] BIOMASS Theme 3 Forest Working Group. Model-data Intercomparison scenario. Version 1.0, IAEA, Vienna, 1998. 